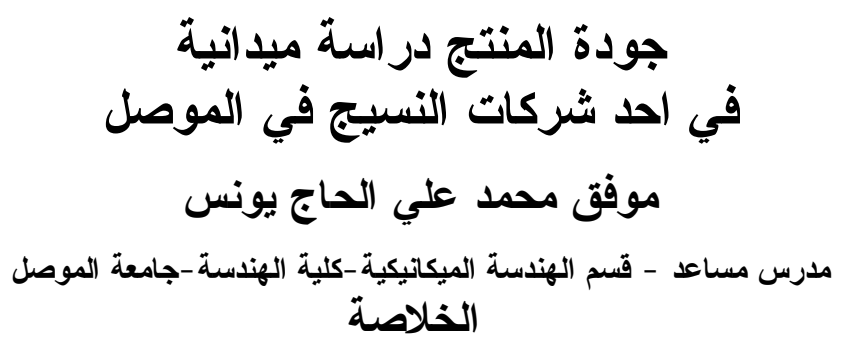

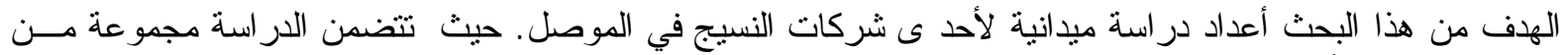

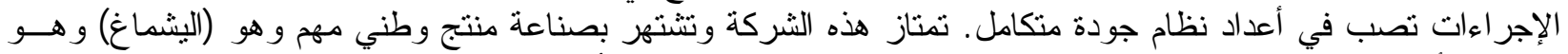

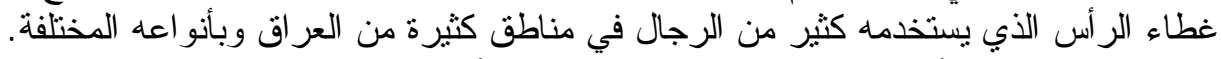

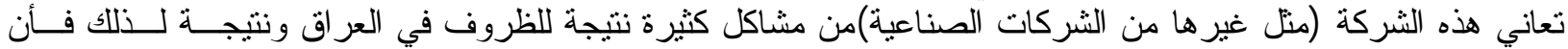

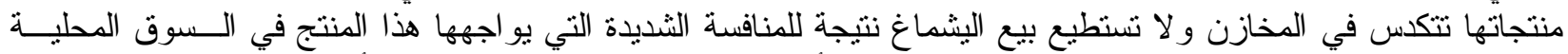

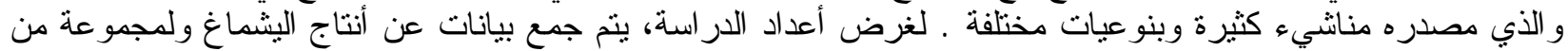

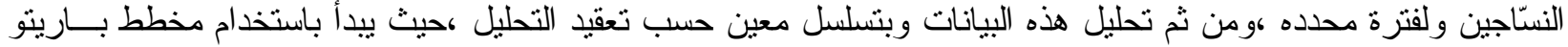

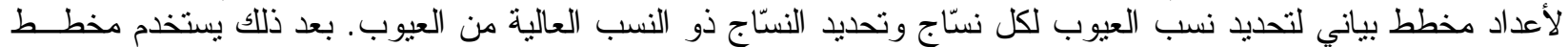

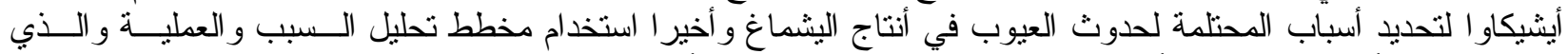

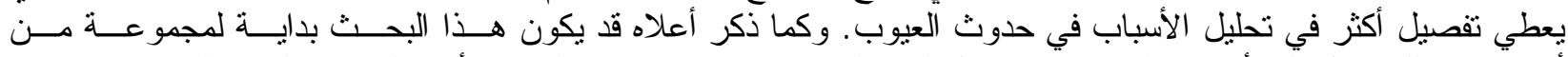

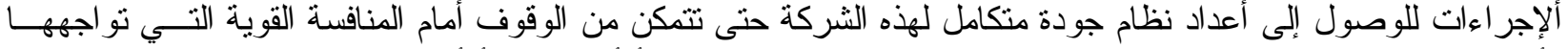

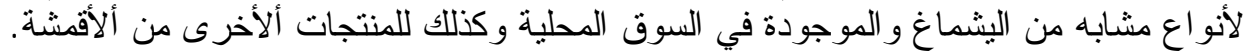

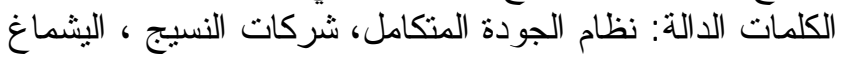

\title{
Field study to Improve Quality of The Product in One of Weaving Companies in Mosul
}

\author{
M.M.A.Younis \\ Assistant Lecturer - Mech. Eng. Dept. - Coll. Of Eng. - Univ. of Mosul
}

\begin{abstract}
The goal of this paper is to prepare a field study for one of the famous weaving companies in Mosul, so that arranging at the end a Total Quality Management System (T Q M) system .This company is famous in producing one of the important national product YASHMAG, the head cover for men wearied in most of the regions of Iraq.

This company (like other industrial companies)suffer from a lot of problems due to circumstances in Iraq, as a result there products will accumulated in their stores, also there is a great compotation from the similar products in the market, which imported to Iraq from different places with different qualities..

In order to make a T Q M system, the study starts by collecting production data for a group of weaving labor how produce Yashmag and for a certain period of time, then analysis of these data using Pareto chart ,Ishikawa chart and Cause Analysis and Process Analysis chart.

This work could be a first step towards making T Q M system for this company in order to keep the company stand still against the great compations of similar products of Yashmag in the market.
\end{abstract}

Key words : Total Quality System, Weaving Companies ,Yashmag 


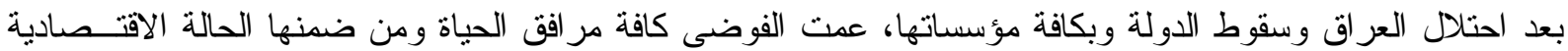

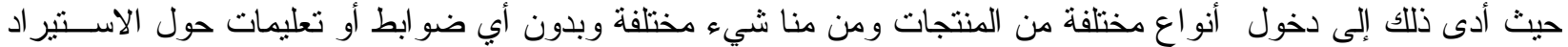

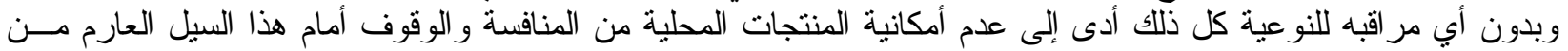

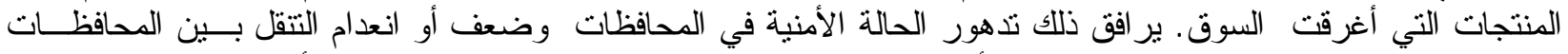

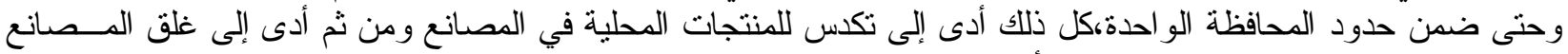

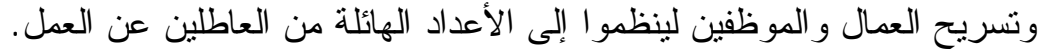

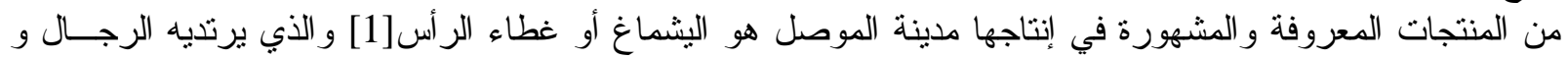

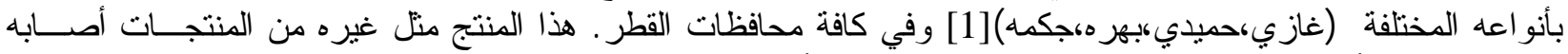

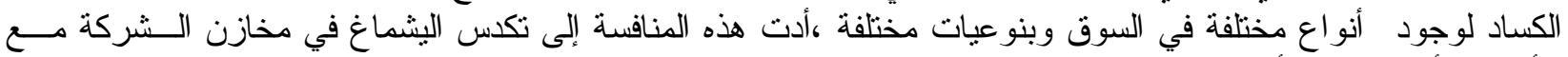

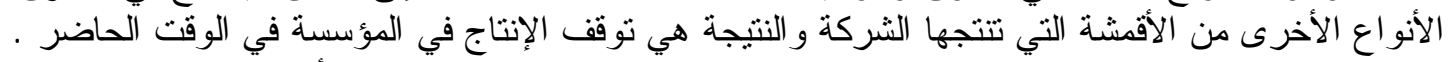

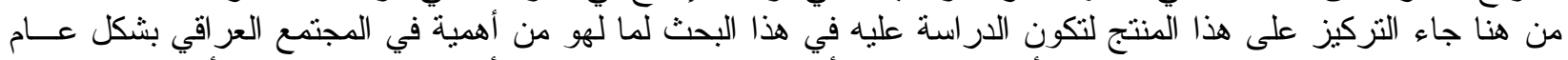

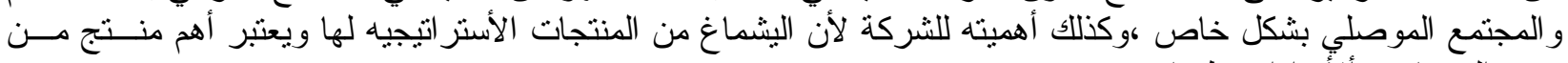

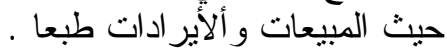

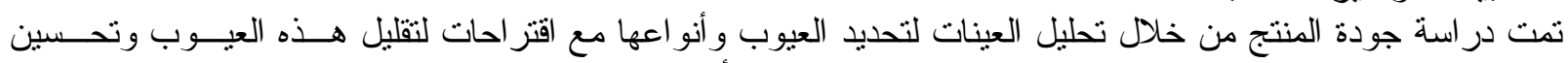

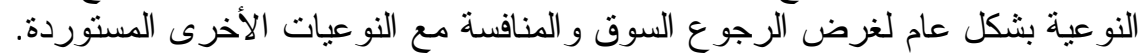

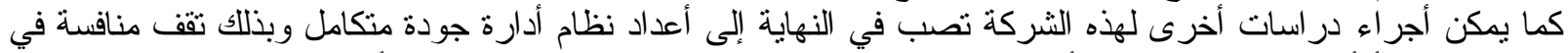

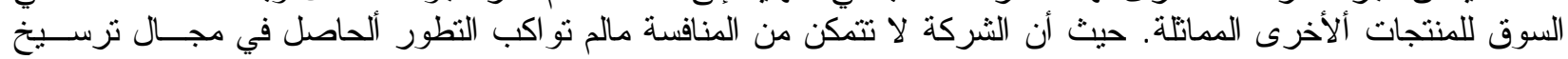

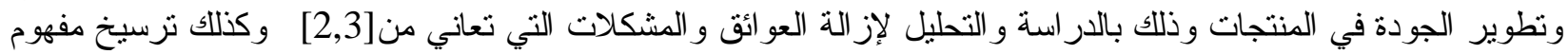

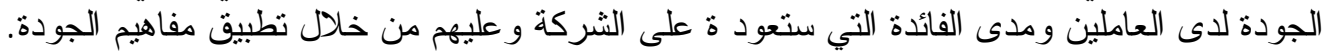

غطاء الر أس أو ما يسمى باليشماغ،هو من أهم مكملات الزى الوطن الوطني التقليدي في العراق وكذللك في بعض الدول

اليشماغ

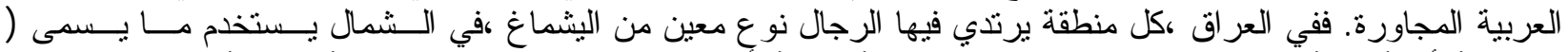

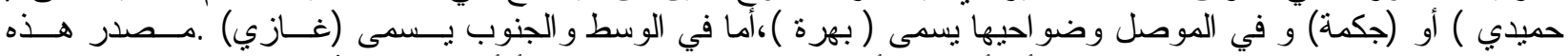

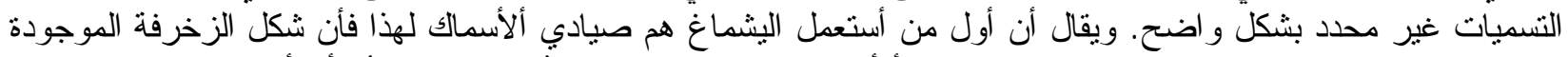

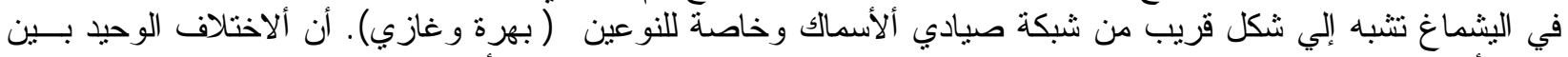

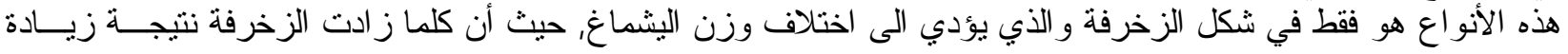

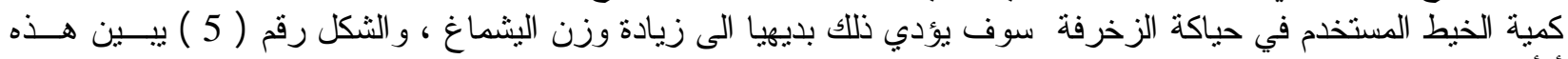

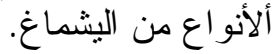

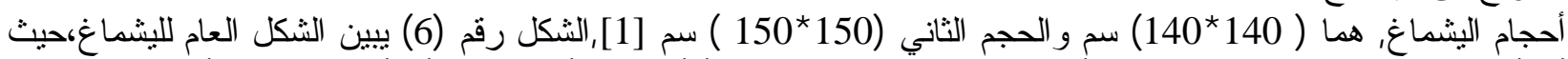

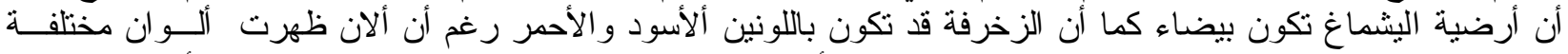

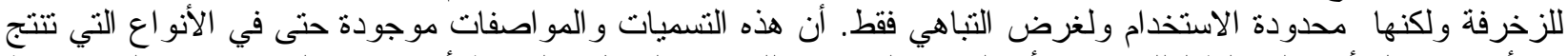

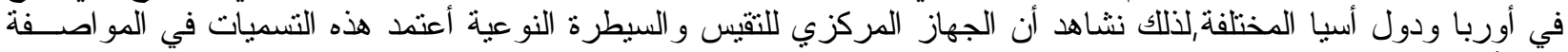
التي أعدها لليشماغ وردياغ

أهم العيوب التي تظهر في اليشماغ واغواغ وأسبابها:

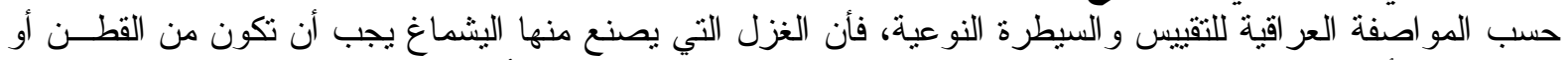

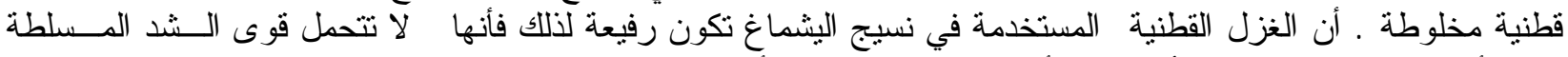

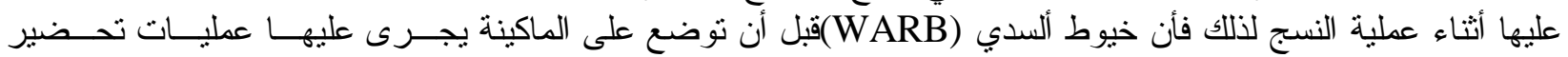

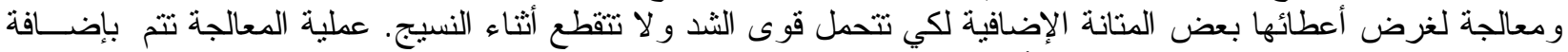

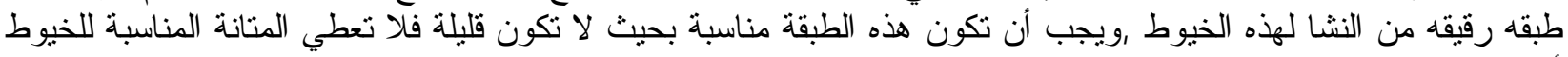
أو تكون كثيرة تؤدي إلى التصاق الخداق الخيوط مع بعضها. 


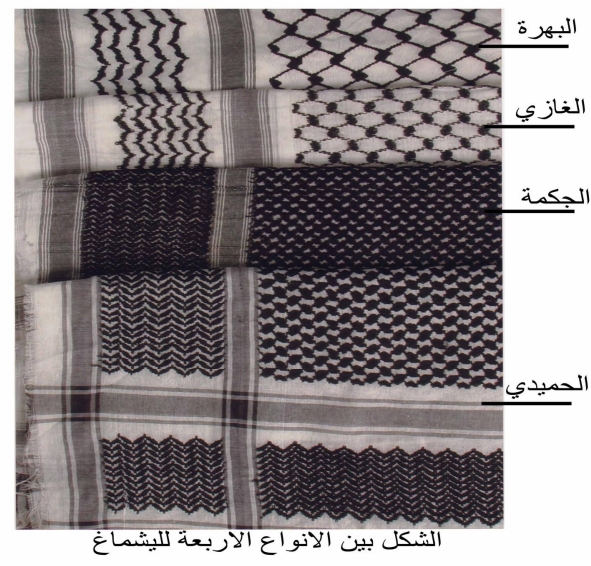

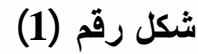

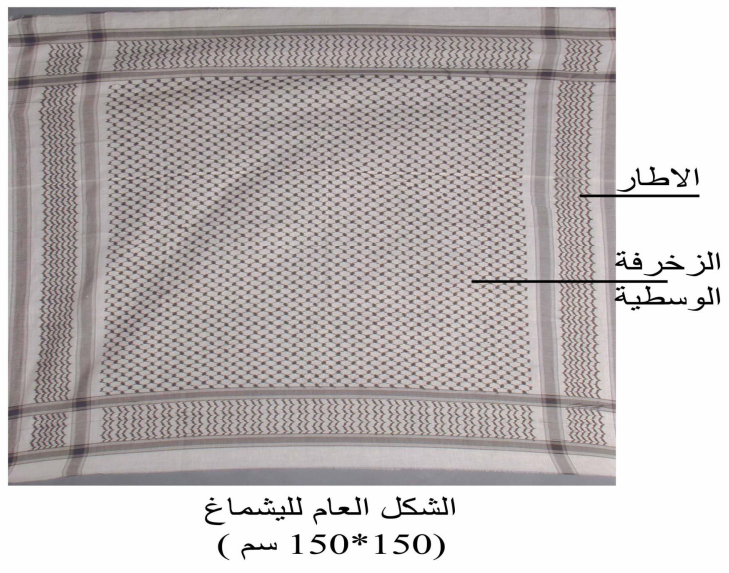

\section{شكل رقم (2) (2)}

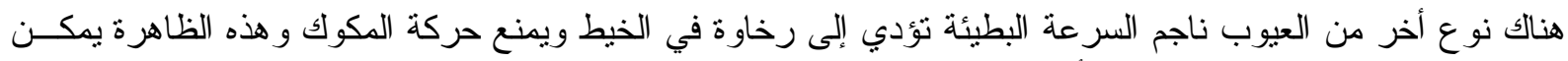

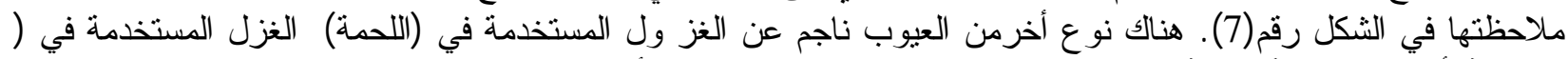

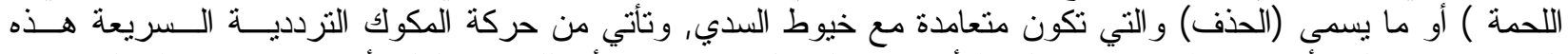

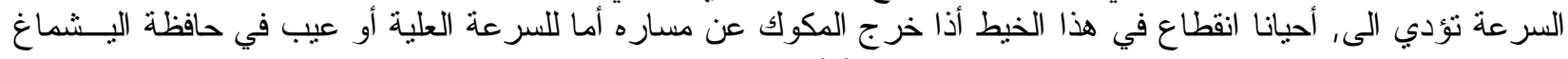

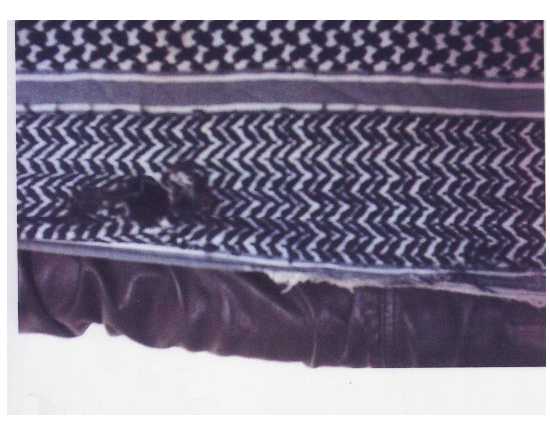

شكل رقم (4) عيب نتيجة سرعة المكوك وبالتالي إلى ظهور عيب في اليشماغ كما في الثكل رقم (8).

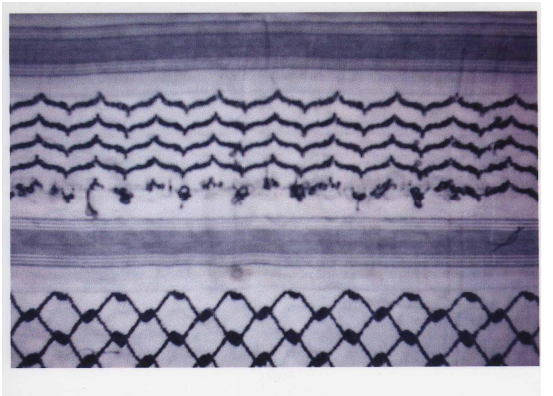

شكل رقم (3) عيب نتيجة رخاوة في الخيط 


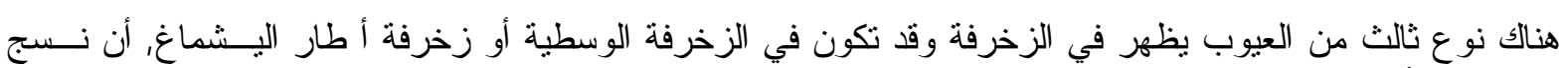

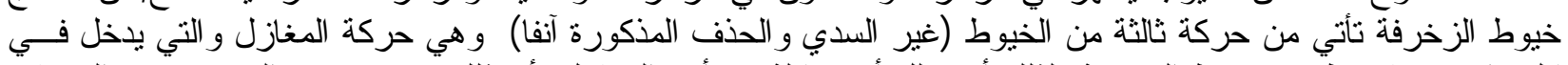

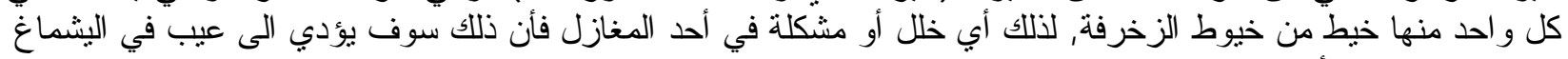
هذا النوع يظهر للأسباب التالية: 1 - أما بسبب اعوجاج في واحد ألوالئ أو أكثر من المغازل

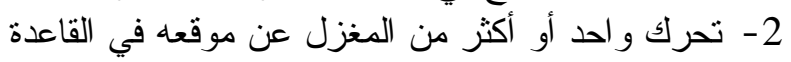

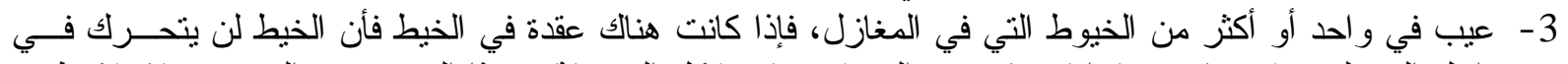

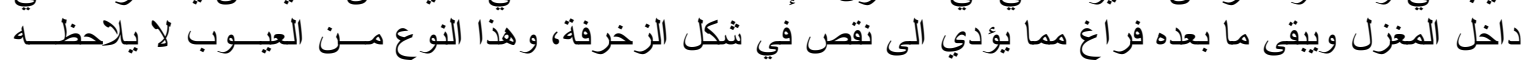

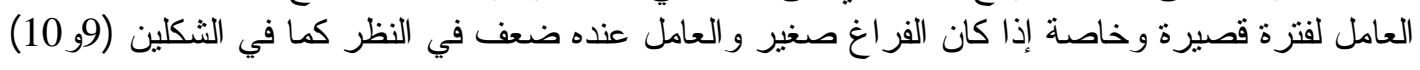

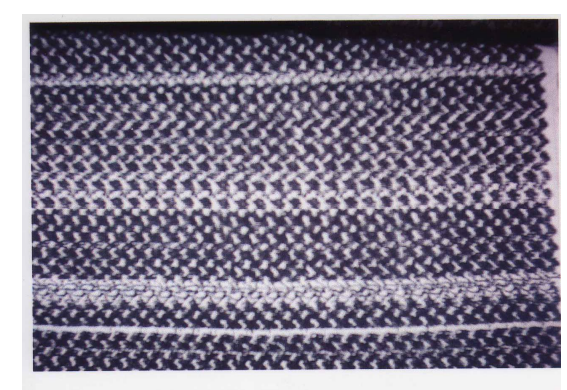

شكل رقم(6) عيب نتيجة خلل في المغازل

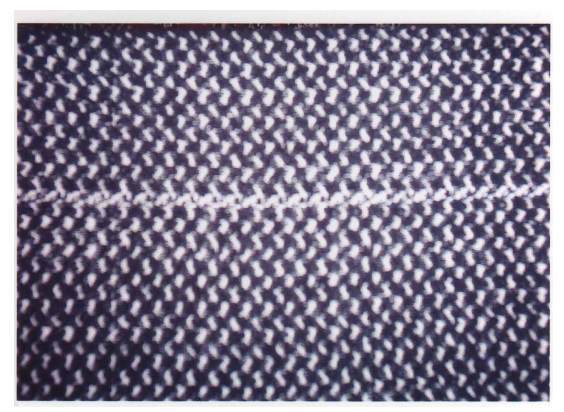

شكل رقما 5) عيب نتيجة خلل في المغازل

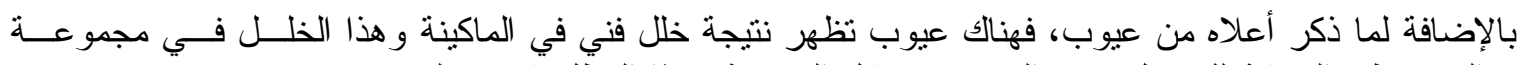

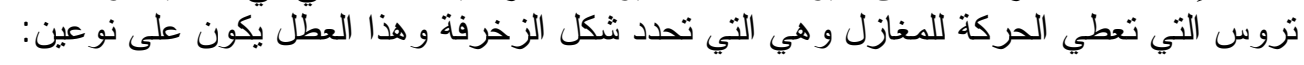

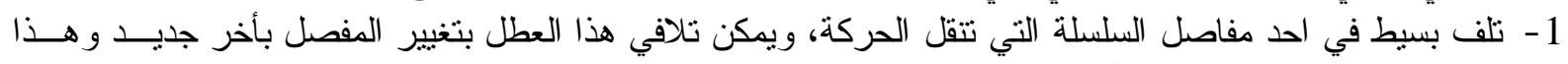

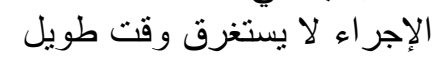

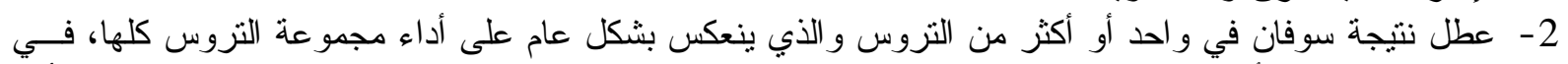

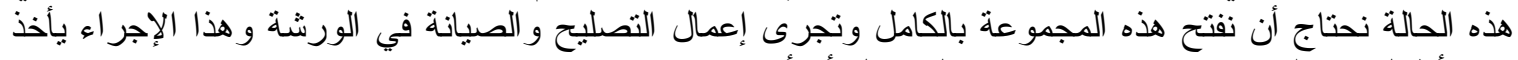

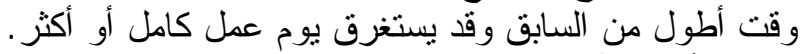

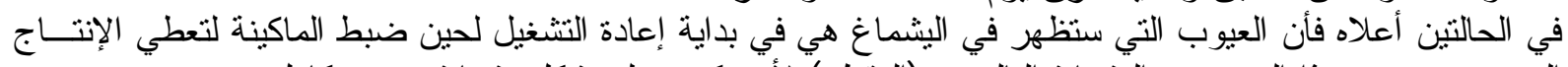

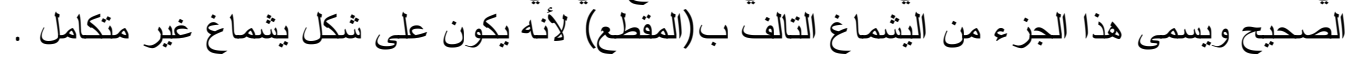

\section{حلقات ضبط الجودة: [ 4، 5، 6 ]}

مجموعة من الأشخاص نتر اوح بين 3 ـ 10 أفر اد ويجب أن ينتمي أعضاء الحلقة الو احدة إلى مكان عمل و واحد لكي

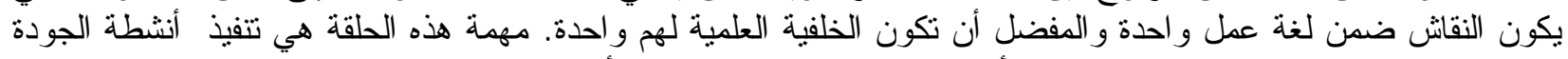

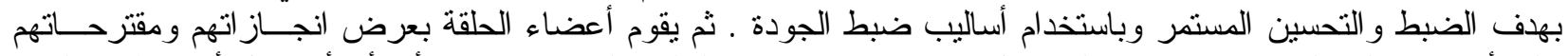

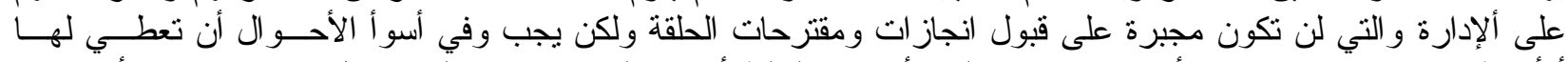

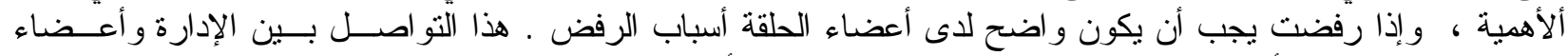
الحلقات يعطي دعما للأعضاء بالاستمر ار بالتطوير و الوصول إنجاء إلى أفضل النتائج التي تخدم المؤسسة.

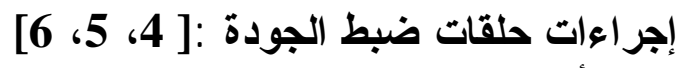

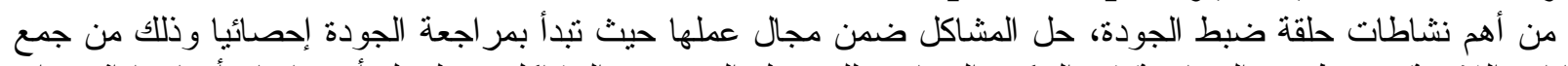

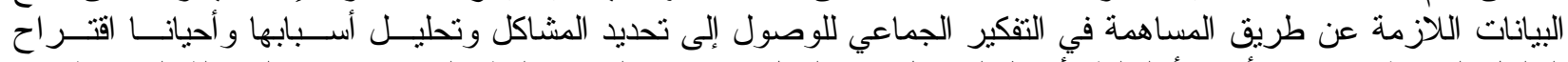

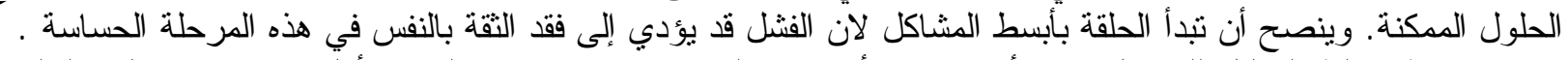

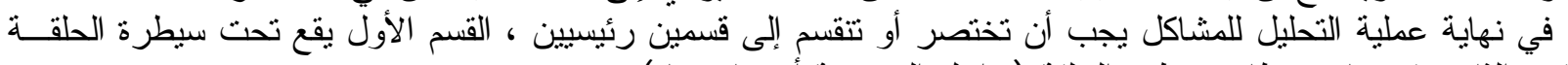

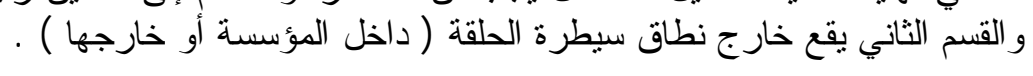




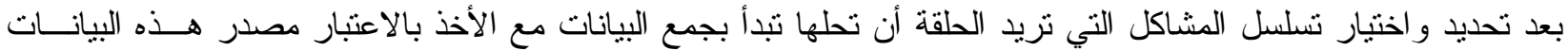

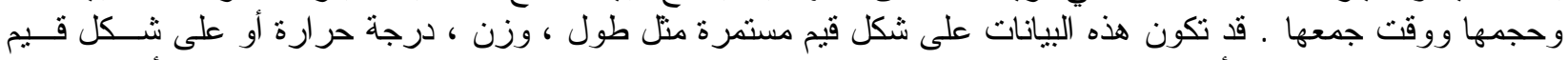

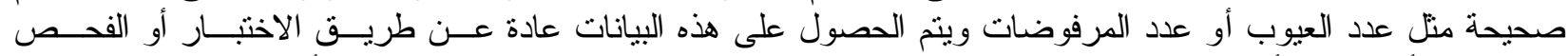

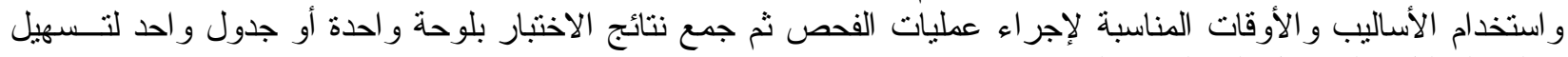
عملية التحليل و الوصول إلى النتائج المناسبة . لإنيا

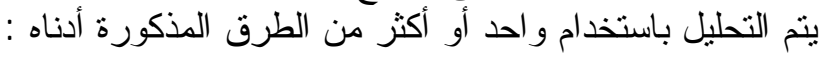

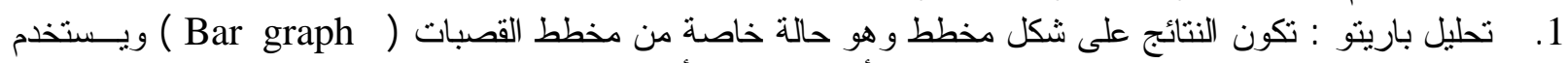

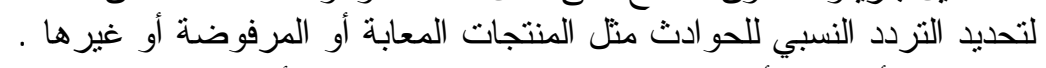

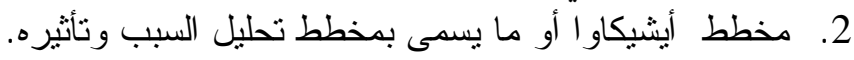

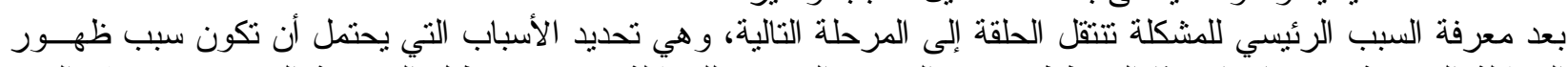

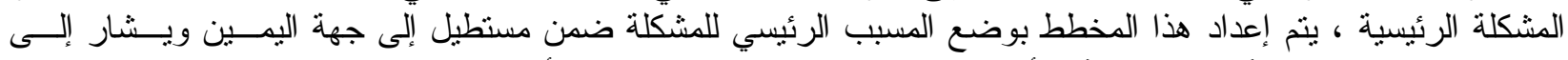

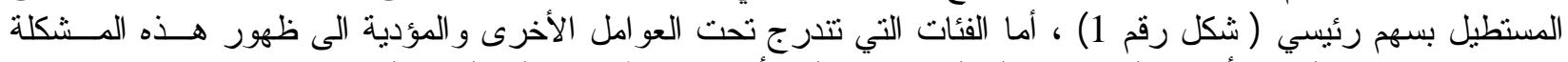

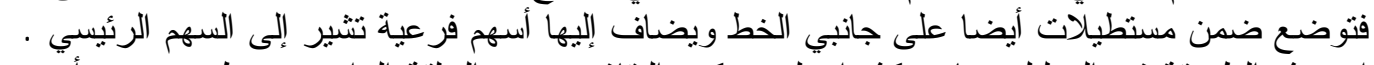
إن هذه الطريقة في التحليل تساعد كثير ا على نزكيز النقاش ضمن الحلقة الواحدة وتعطي صورة أوضح عن عن أسباب المشكلة

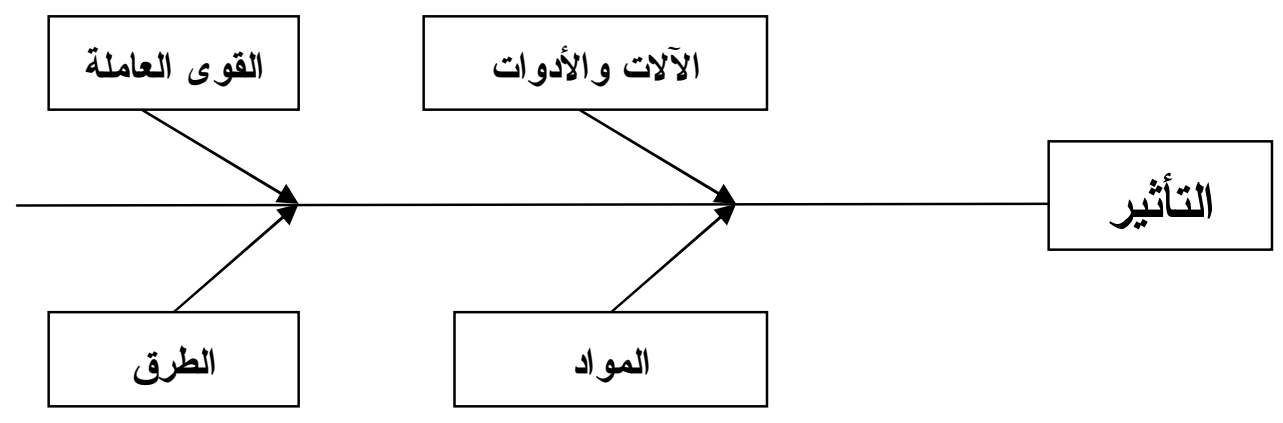

\section{شكل رقم (7) الشكل العام لمخطط أيشيكاوا}

3. مخطط تحليل السبب وتحليل العملية : أن بعض المشاكل تحتاج الى تحليل أعمق وتفصيل أكثــر مــن التــي فــي

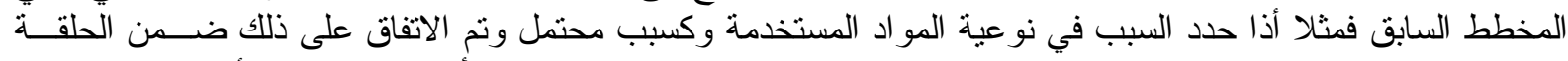

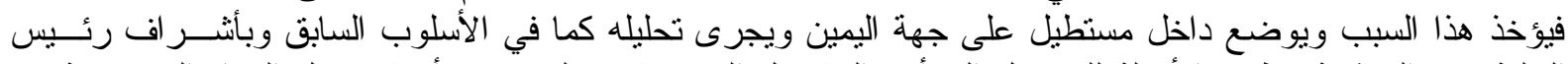

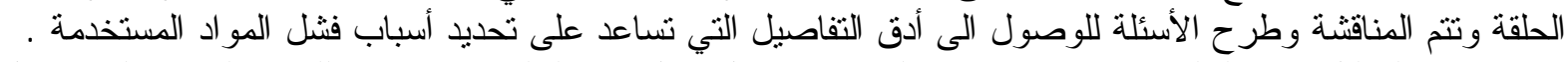

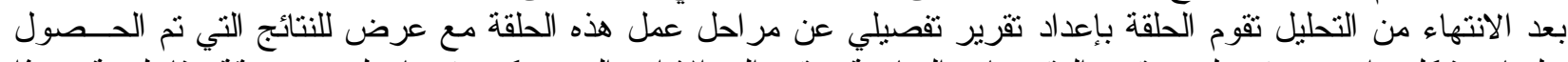

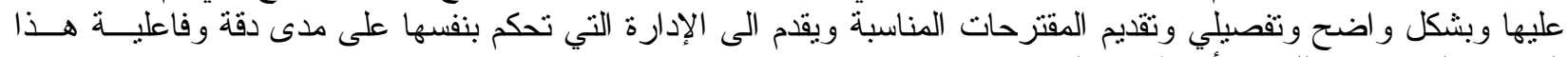
النقرير على إن لا تقلل من أهمية هذا الجهد .

$$
\begin{aligned}
& \text { عينة الار اسةة : ع العين }
\end{aligned}
$$

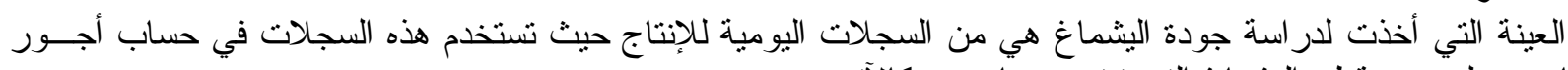

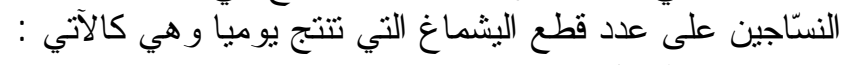

$$
\begin{aligned}
& \text { 1. } \\
& \text { 2. الإعال في الجدول يعملون على ثلاثة مكائن نسيج. }
\end{aligned}
$$

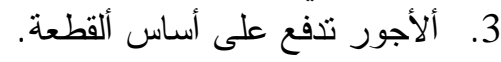

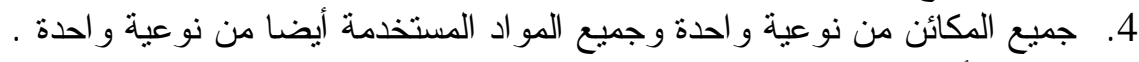

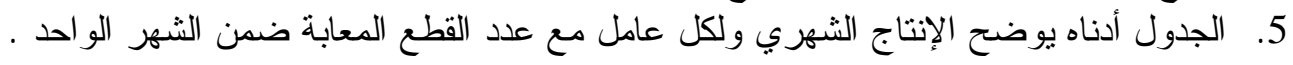




\begin{tabular}{|c|c|c|c|c|c|c|c|c|c|c|c|c|}
\hline \multicolumn{2}{|c|}{ حزيران } & \multicolumn{2}{|c|}{ أيار } & \multicolumn{2}{|c|}{ نيسان } & \multicolumn{2}{|c|}{ آذار } & \multicolumn{2}{|c|}{ شباط } & \multicolumn{2}{|c|}{ كانون الثاني } & \multirow{2}{*}{ العمل } \\
\hline المعيب & الإتتاج & المعيب & الإتتاج & المعيب & الإنتاج & المعيب & الإتتاج & المعيب & الإنتاج & المعيب & الإتتاج & \\
\hline 4 & 524 & 4 & 591 & 10 & 645 & 7 & 584 & 4 & 626 & 7 & 509 & محمد \\
\hline 8 & 497 & 4 & 442 & 2 & 561 & 7 & 490 & 4 & 504 & 6 & 390 & صالح \\
\hline 5 & 565 & 5 & 615 & 11 & 540 & 1 & 572 & 4 & 485 & 4 & 455 & هاشم \\
\hline 8 & 425 & 5 & 398 & 9 & 301 & 8 & 421 & 7 & 441 & 7 & 345 & احمد \\
\hline 7 & 345 & 7 & 341 & 7 & 278 & 5 & 408 & 6 & 395 & 8 & 250 & إدريس \\
\hline \multicolumn{2}{|c|}{25} & \multicolumn{2}{|c|}{24} & \multicolumn{2}{|c|}{23} & \multicolumn{2}{|c|}{24} & \multicolumn{2}{|c|}{18} & \multicolumn{2}{|c|}{23} & العمل في أيام \\
\hline
\end{tabular}

\begin{tabular}{|c|c|c|c|}
\hline نسبة العيوب & عدد القطع المعابة لستة أشهر & الإنتاج الكلي لستة أشهر & اسم العامل \\
\hline$\% 1.03$ & 36 & 3479 & محمد \\
\hline$\% 1.1$ & 31 & 2884 & صالح \\
\hline$\% 0.92$ & 30 & 3232 & هاشم \\
\hline$\% 1.25$ & 44 & 2331 & احمد \\
\hline$\% 1.32$ & 40 & 2017 & إدريس \\
\hline
\end{tabular}

\section{تطبيق حلقات ضبط الجودة :}

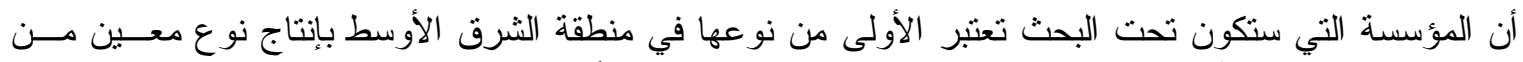

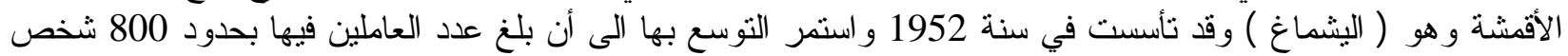

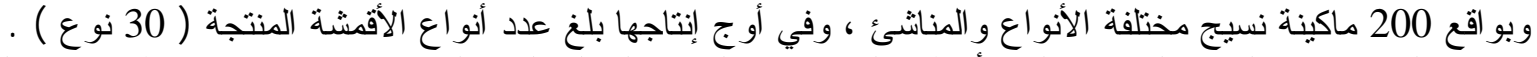

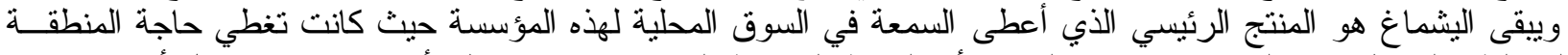

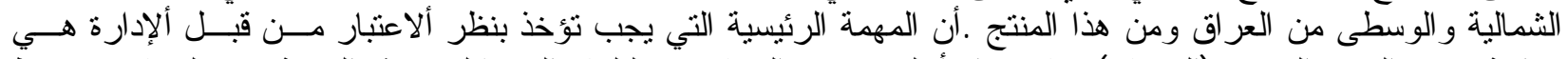

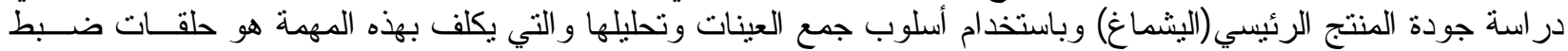
الجودة التي يتم اختيار أعضائها من قبل ألإدارة.

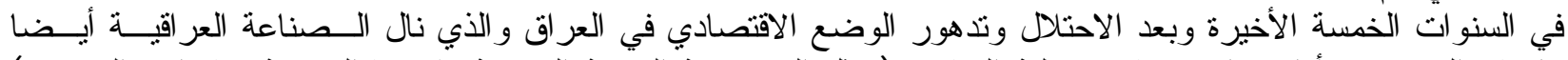

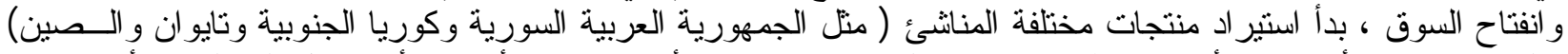

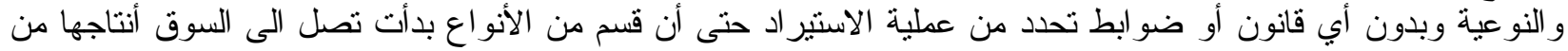

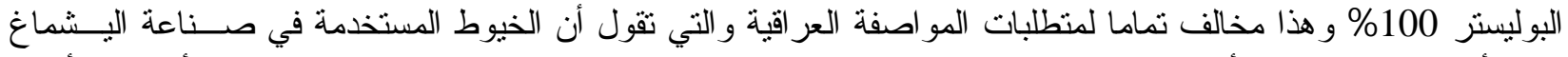

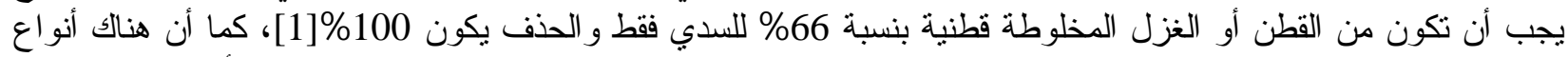

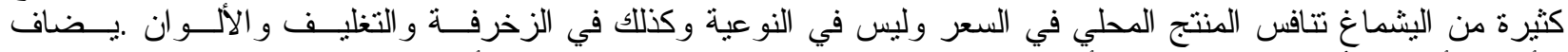

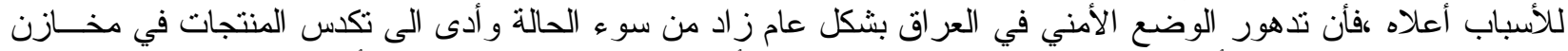

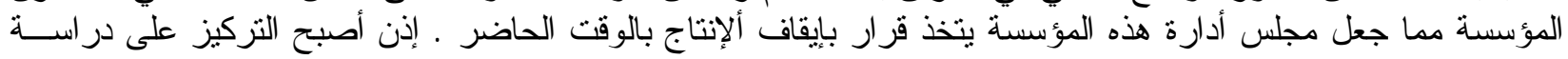




\section{الحاج يونس : جودة المنتج دراسة ميدانية في احد شركات النسيج في الموصل ...}

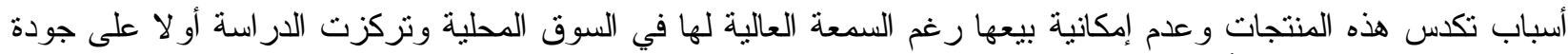

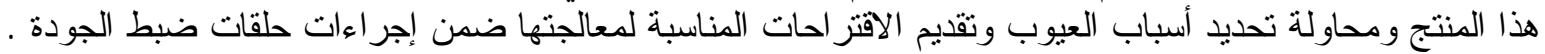

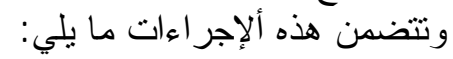

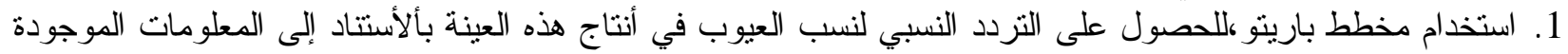

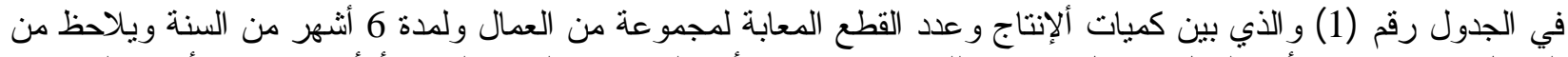

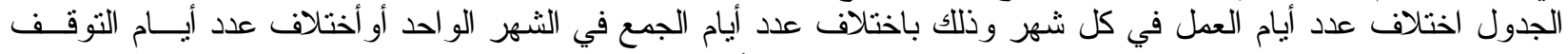

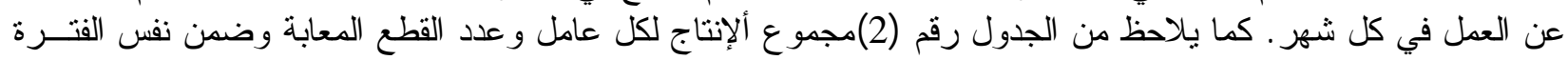

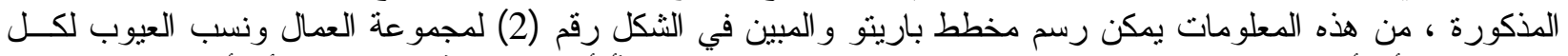

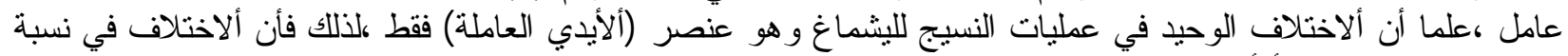

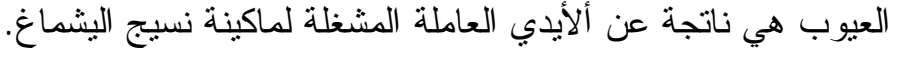

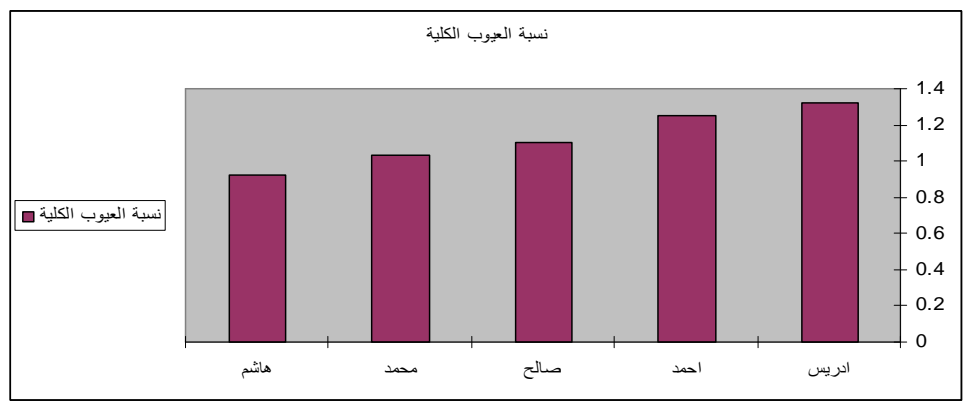

شكل رقم (8) :مخطط باريتو لعينة الدراسة

2.استخدام مخطط أيشيكاو ا، أو مخطط تحليل السبب وتأثيره

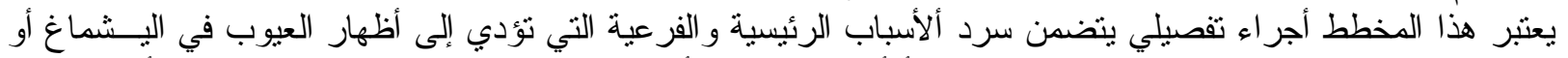

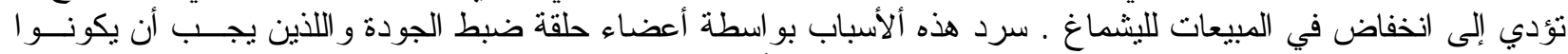

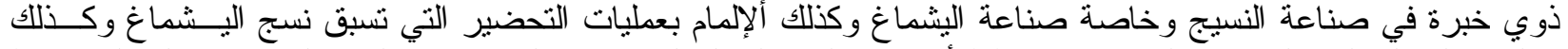

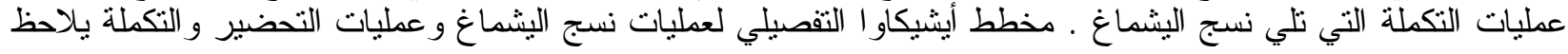

في الشكل رقم (3).

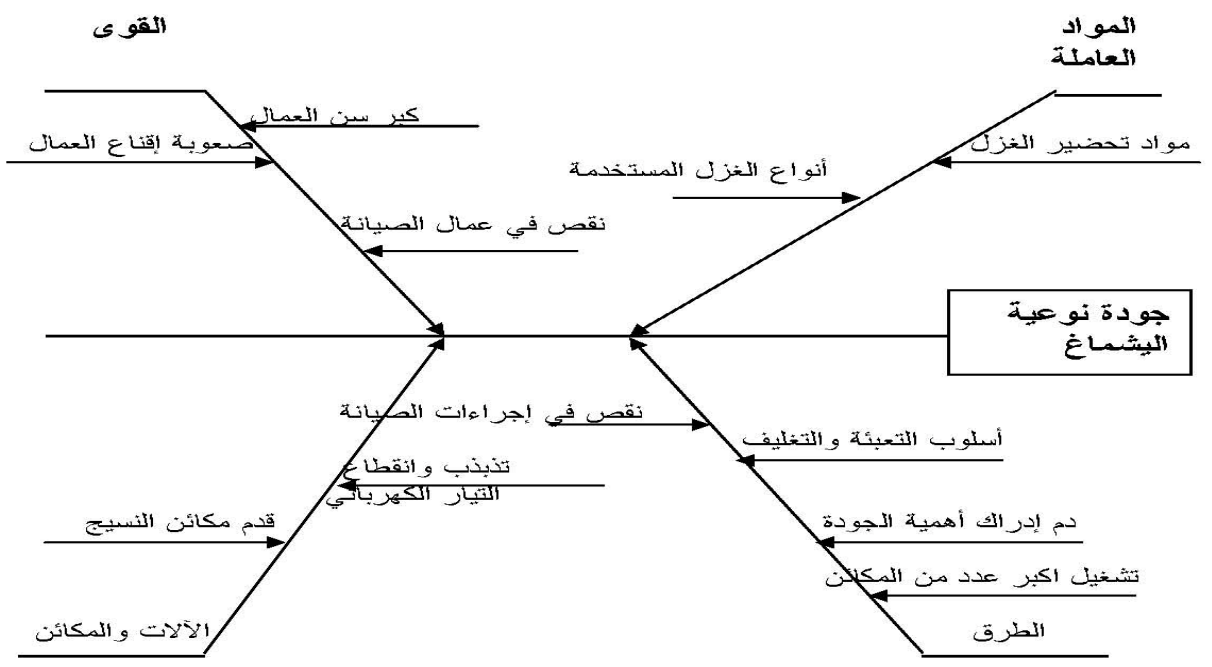

شكل رقم(9) مخطط أيشيكاو العمليات نسج اليشماغ الرئيسية والثانوية 
3.مخطط تحليل السبب وتحليل العملية

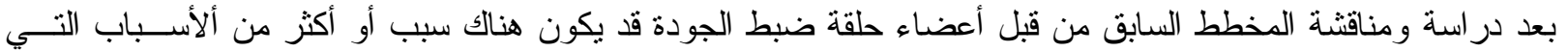

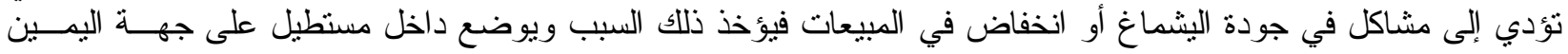

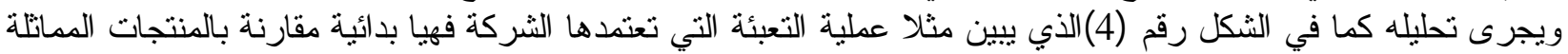
و الموجودة في السوق المحلية

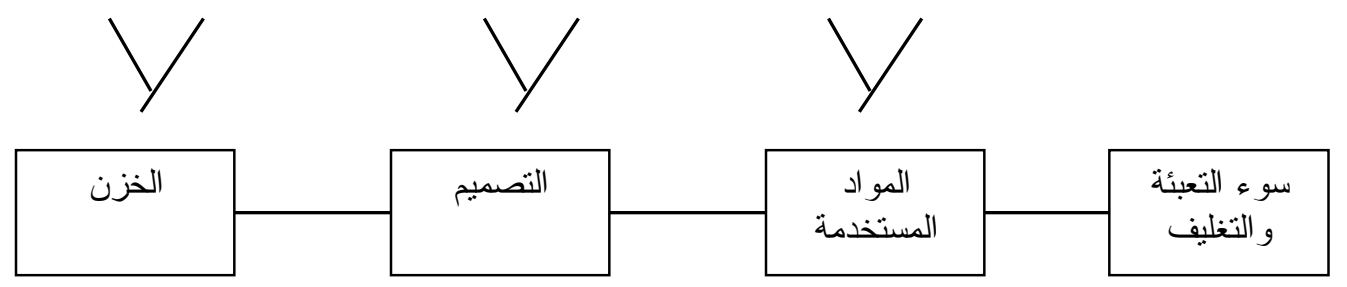

شكل رقم (10) مخطط تحليل السبب وتحليل العملية لعملية التعبئة

\begin{abstract}
المناقشة:

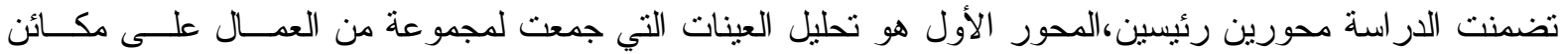

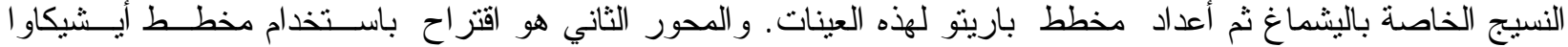

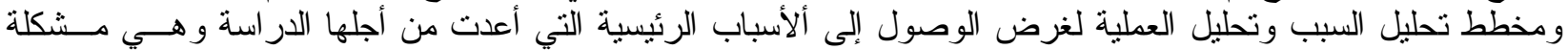

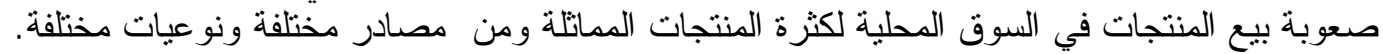

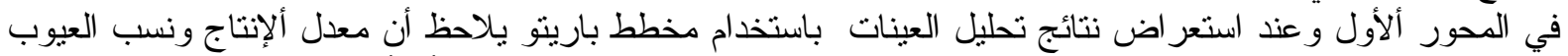

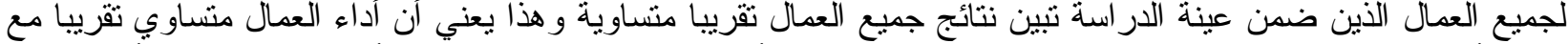

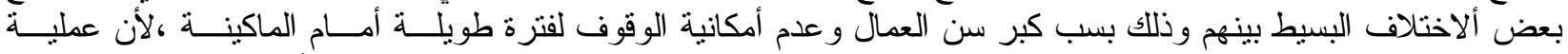

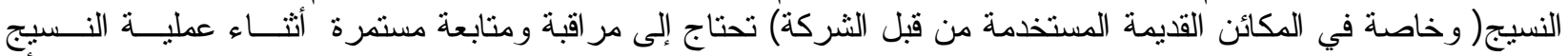

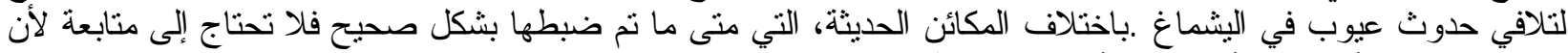

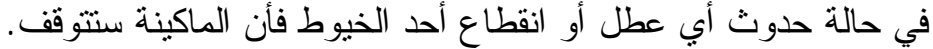

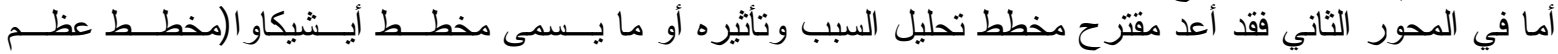

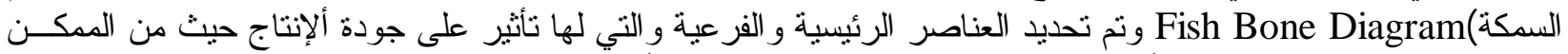

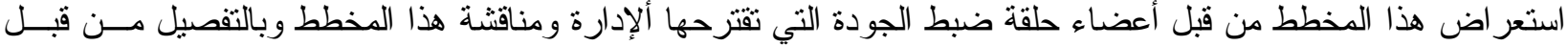

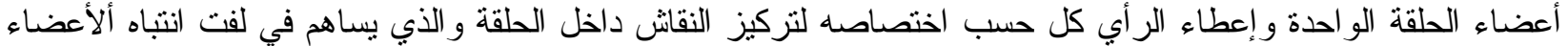

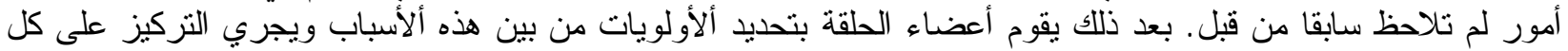

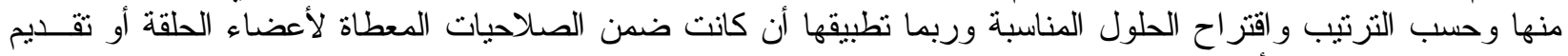
اقتر اح بهذه الحلول إلى ألإدارة.

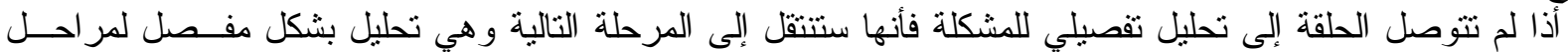

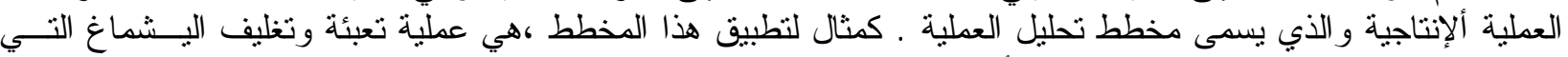

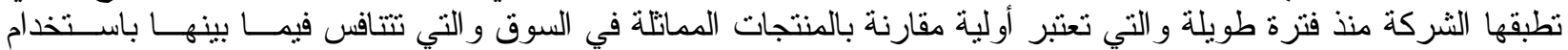

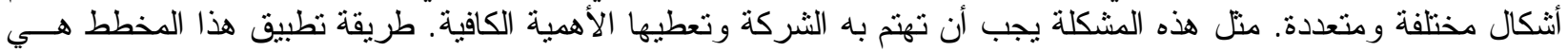

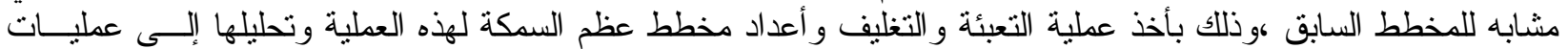

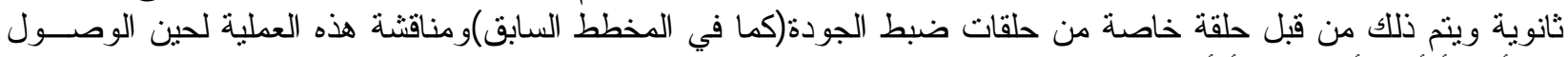

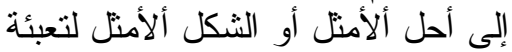
وتغليف اليشماغ لينافس ما موجود في الإن السوق من أشكال مماثلة.
\end{abstract}




\section{الحاج يونس : جودة المنتج دراسة ميدانية في احد شركات النسيج في الموصل ...}

ألاستتناجات و التوصيات:

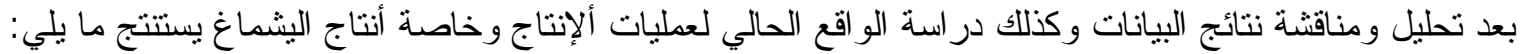

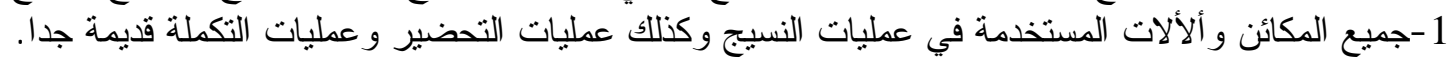

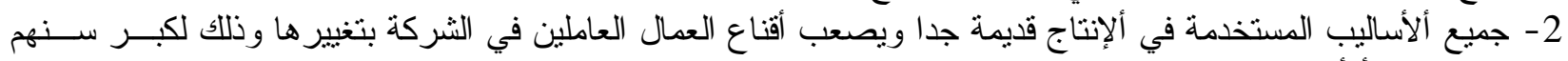
و اعتمادهم هذه ألأساليب منذ فترة طويلة.

3 -عدم وجود أساليب متطورة ألو أقسام خاصة بالسيطرة النوعة فية وإنة إنما استخدام أسليب بدائية في الفحص فقط.

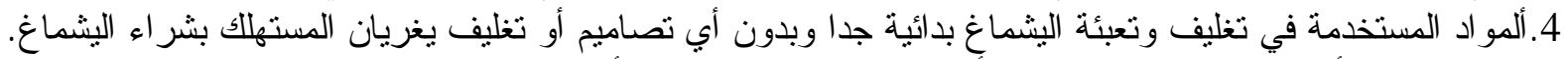

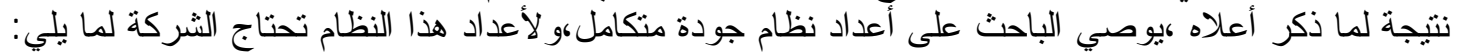

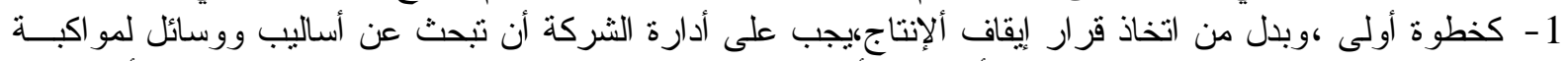

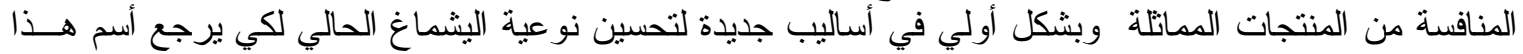

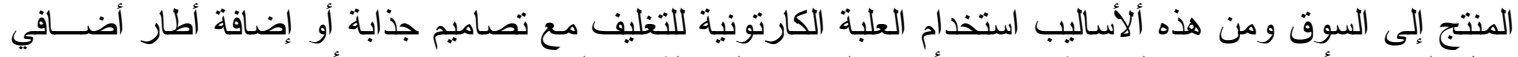

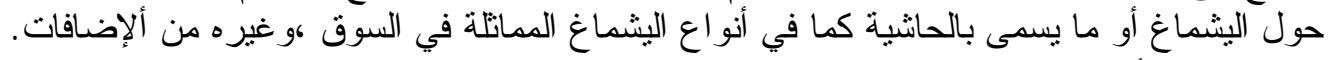

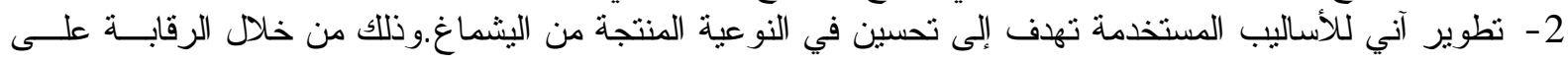

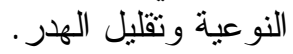

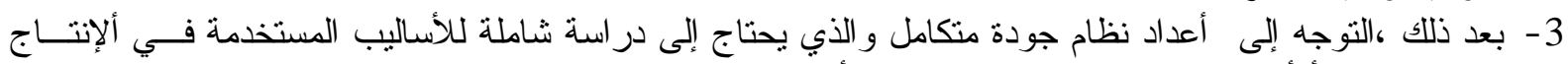

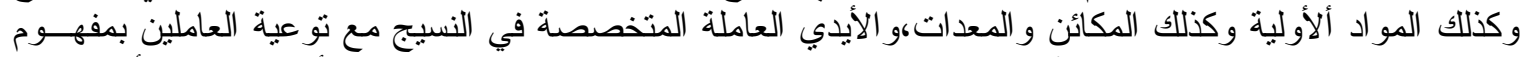

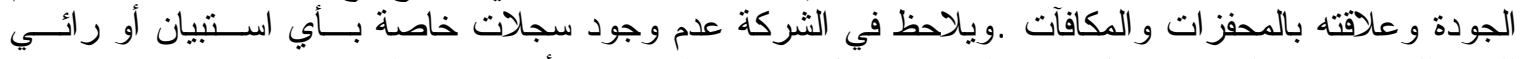
للمستهلك بمنتجات الشركة بشكل عام و اليشماغ بشكل خاص و الذي يجب وأ أن تهنم به الثركة.

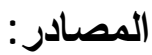
1.الجهاز المركزي للتقييس و السيطرة النو عية،مسودة المو اصفة القياسية رقم 2465للغزل و النسيج -غطاء ألر أس -اليـشماغ .1985 2.رعد غائب عبد الو هاب،خوله محمد علي -تهيئة الثركات الصناعية للحصول على شهادة (ISO 9000)، ألمؤتمر القطري

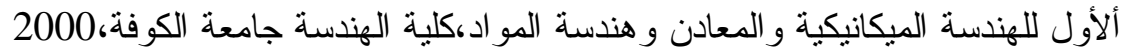

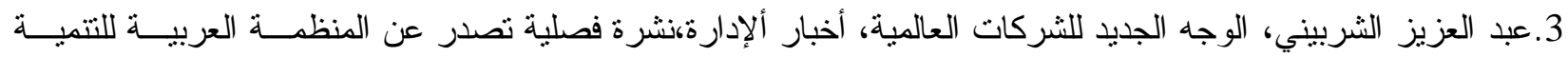

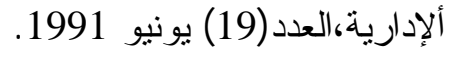

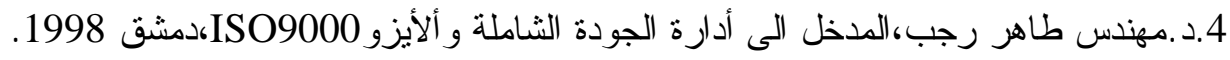

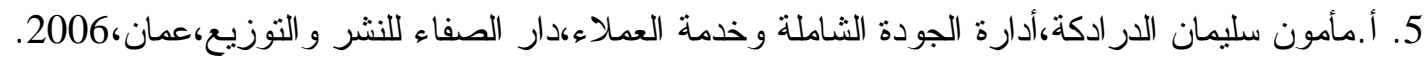
6.محمد نوفيق ماضي، أدارة الجودة مدخل نظام متكامل،مصر ، دارة دار المعارف،

تم اجراء البحث في كلية الهنسة - جامعة الموصل 